\title{
Genetic and clonal diversity for Myrica cerifera along a spatiotemporal island chronosequence
}

\author{
DL Erickson ${ }^{1,3}$ and JL Hamrick ${ }^{1,2}$ \\ ${ }^{1}$ Department of Plant Biology, University of Georgia, Athens, GA 30602, USA; ${ }^{2}$ Department of Genetics, University of Georgia, Athens, \\ GA 30602, USA
}

\begin{abstract}
Changes in genetic diversity and clonal structure were investigated along a spatiotemporal island chronosequence for the shrub Myrica cerifera. On our study site, Hog Island, Virginia, USA, island movement creates a sequence of dune ridges and intervening swales along an east-west axis of the island that produces an age-structured geomorphology. This substrate-mediated age structure, called the chronosequence, superimposes itself upon cohorts of $M$. cerifera that colonize behind nascent dune ridges as they are formed. This chronosequence allowed comparisons of levels of genetic diversity and clonal structure among different aged cohorts of $M$. cerifera. We observed little change in allelic diversity along the chronosequence and no evidence for
\end{abstract}

heterosis, although there was moderate change in genotypic diversity. The spatial distribution of individuals within 10 plots established along three transects intersecting the island chronosequence identified a nonrandom spatial distribution of individuals in all cohorts, with increasing aggregation of above-ground stems into multistemmed clusters in the older sites. This aggregation of individuals did not correspond to a significant increase in clonal growth with cohort age, nor was there significant spatial genetic autocorrelation within any of the plots.

Heredity (2003) 90, 25-32. doi:10.1038/sj.hdy.6800172

Keywords: Myrica cerifera; genetic diversity; clonal structure; heterosis; spatial autocorrelation; genetic autocorrelation

\section{Introduction}

The distribution of genetic diversity among plant populations has been extensively investigated, with particular emphasis on its spatial distribution (Hamrick and Godt, 1996). A few studies have examined the temporal distribution of genetic diversity, typically comparing cohorts within populations, and sometimes different aged populations (Linhart et al, 1981; Fore et al, 1992; Giles and Goudet, 1997; Mahy et al, 1999). Results from these studies vary, but some general conclusions are that younger cohorts often have lower genetic variation than older cohorts, and in particular younger cohorts exhibit less individual heterozygosity than older cohorts. Mechanisms that account for such patterns are rarely directly tested. It is often concluded that young cohorts or populations contain a subset of the genetic diversity observed in the larger, surrounding global populations, and that over time gene flow augments the limited genetic base (Dumolin-Lapegue et al, 1997; Giles and Goudet, 1997). Temporal changes in genetic diversity within a cohort where recruitment has ceased cannot be explained by gene flow, whereupon overdominant selection is often invoked.

The importance and prevalence of overdominant selection in natural plant populations has been a subject of debate (Mitton and Grant, 1984; Savolainen and

Correspondence: DL Erickson, Department of Biology, University of Maryland, College Park, MD 20742,USA. E-mail: de51@umail.umd.edu ${ }^{3}$ Current Address: Department of Biology, University of Maryland, College Park, MD, USA.

Received 3 January 2002; accepted 3 August 2002
Hedrick, 1995; Schierup, 1998). Although the observation of increased heterozygosity with age is common in natural populations of many woody plants (Bush and Smouse, 1992), the mechanisms responsible for increased heterozygosity are often unknown. Recent studies have suggested that selection against inbred individuals results in increased heterozygosity (Dudash and Carr, 1998). However, regardless of the mechanism and specific locus of selection, documenting the occurrence and prevalence of heterosis, and its magnitude in natural populations, remains relevant because of its potential importance in maintaining genetic diversity within populations.

Many factors other than heterosis affect levels of genetic diversity in natural populations. One such factor is clonal growth (Widen et al, 1994). While many plant species regenerate clonally, rarely is this taken into account when addressing levels and distribution of genetic diversity. Clonal structure may reduce the number of genetically distinct individuals within a population and hence decrease the genetic effective population size, increasing genetic drift. Clonal structure may also result in positive spatial genetic autocorrelation, which may be falsely attributed to limited propagule dispersal distance or kin-structured colonization (Ingvarsson, 1998; Kalisz et al, 2001). Alternatively, if clonal growth and overdominant selection operate in concert, an excess of heterozygosity may be observed together with increased allelic diversity within populations and decreased differentiation among them. While clonal and asexual populations may have similar levels of genetic diversity relative to exclusively sexually reproducing species (Ellstrand and Roose, 1987; Parker 
and Hamrick, 1992), the effect of increasing clonal structure on genetic diversity is not widely known. Since clonal plants begin as a single unit and then replicate to make a genet composed of multiple, genetically identical ramets, it is reasonable to expect temporal genetic changes within a clonally reproducing population, particularly with regard to genotypic diversity. Genetic studies of clonal plants have investigated diversity at a single stage of population development; thus how increased clonal growth affects populations is unknown.

In this study, we examine populations of the shrub Myrica cerifera that inhabit a barrier island which shows a spatially distributed age structure referred to as a chronosequence. Thus, areas that were colonized at different times remain separated from one another and serve as a snapshot of a population through time. This spatiotemporal chronosequence allows us to address how changes in clonal structure along the chronosequence affect allelic and genotypic diversity. Also, we describe changes in heterozygosity with age and how that process interacts with changes in clonal structure to alter patterns of genetic diversity at both spatial and temporal scales.

\section{Materials and methods}

\section{Study species}

Myrica cerifera L. (Myricaceae) is an evergreen dioecious, perennial shrub that reaches $6 \mathrm{~m}$ in height; it is common in coastal or disturbed inland sites in the Southeastern US (Radford et al, 1968). Fruits of $M$. cerifera are singleseeded drupe, small, $\approx 4 \mathrm{~mm}$ in diameter, and are covered by a resinous waxy substance from which the species takes its common name, wax myrtle. Fruits mature in early fall and are eaten by migratory bird species, particularly Dendroica coronata (D. Erickson, personal observation). Seeds do not dehisce, and those that remain attached to the plant begin to lose their ability to germinate after 9 months (unpublished data). Myrica cerifera has a symbiotic association with a nitrogen-fixing bacterium (Frankia sp.), which is suggested to facilitate colonization of nutrient-poor sandy soils (Young et al, 1992).

\section{Study site}

Our study site was Hog Island of the Virginia Coast Reserve, which is part of the Long Term Ecological Research (LTER) network, and located approximately 7 miles off the coast of Virginia, USA (Figure 1a). Hog Island has an unusual geomorphology defined by a distinct east-west chronosequence of dunes (Hayden et al, 1991). Island movement results in a succession of dune ridges built over time, which are punctuated by high saline swales that separate vegetation growing on the dunes (Figure 1b). In general, studies of vegetation on Hog Island have observed that elevation controls the distribution of most plants. Many plant species, including $M$. cerifera, cannot grow in high saline depressions, yet require a low enough elevation for their roots to reach an underground lens of freshwater (Young et al, 1994; Hayden et al, 1995).

The combination of the geomorphology of Hog Island and the restriction of plants to mid-elevation sites results

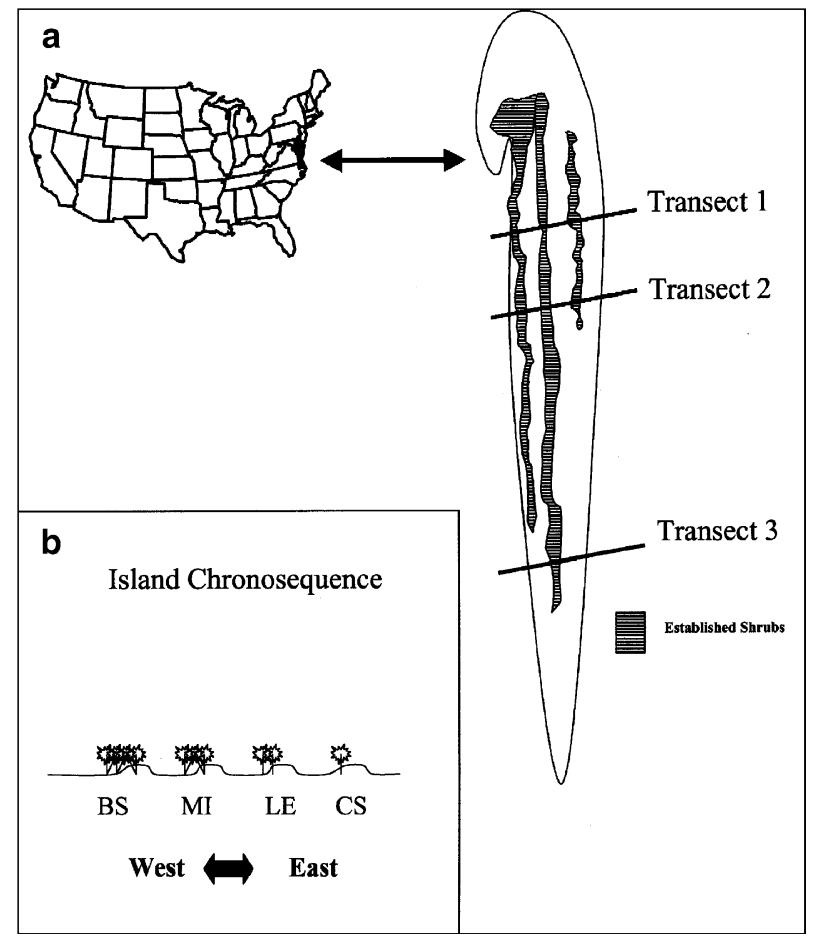

Figure 1 (a) Location of the Hog Island field site relative to the continental US, with a larger schematic of Hog Island showing the position of the mature stands of shrubs with each of the three transects. (b) A diagram of the island chronosequence showing the topology that regulates the distribution of the shrubs and the location of the field plots. Other images of Hog Island and the distribution of vegetation can be viewed at the VCR LTER website: www.atlantic.evsc.virginia.edu.

in the age structure of the chronosequence superimposing itself upon the population structure of $M$. cerifera. Thus we find $M$. cerifera to be highly age structured along the east-west chronosequence of Hog Island (Shao et al, 1998). On Hog Island, M. cerifera is the dominant woody species, and other common members of maritime forests are largely absent (Shao et al, 1998). Thus, the potential effect of other species upon the maintenance of age structure of $M$. cerifera on Hog Island is eliminated. Additionally, $M$. cerifera is largely unaffected by even severe storms such that environmental disturbance has not significantly altered the age structure of the shrubs on Hog Island (Young et al, 1995a,b). Likewise, Crawford and Young (1998) found that $M$. cerifera did not replace itself in canopy gaps, a property that reinforces the substrate-mediated age structure upon the plant population.

There are four major zones of $M$. cerifera vegetation: (1) a colonizing zone (CS) of shrubs $<10$ years old where seedling recruitment continues; (2) a leading edge (LE) of thicket expansion where the 15 to 25year-old canopy is largely closed and recruitment is very limited; (3) a mid-Island site (MI) composed of 40 to 60-year-old-plants where the canopy is closed and no recruitment occurs; (4) a bay side (BS) site with plants of $>60$ years old, which is established on the most westward and oldest above-ground habitat on the island. 
Data collection

In 1995, three transects intersecting $M$. cerifera along the chronosequence on Hog Island were established. Two transects intersect all four of the age zones of $M$. cerifera, while a third at the more narrow south end of the Island intersected only the CS and MI sites. Plots were square with a length of $15-20 \mathrm{~m}$ as needed to include $\sim 45$ above-ground stems in the sample. Every stem was mapped, tagged and was sampled for leaf tissue for allozyme analyses. Tissue was kept cold during transport to the University of Georgia (1-3 days), where enzymes were extracted. Enzymes were extracted from leaf tissue in a phosphate-PVC buffer (Mitton et al, 1979), and the extract was absorbed onto filter paper wicks and stored at $-70^{\circ} \mathrm{C}$ until analysis. Samples were subjected to electrophoresis for $3-5 \mathrm{~h}$ in $10 \%$ starch gels, stained and scored for polymorphism.

Six polymorphic allozyme markers were used in the analysis. These enzymes were phosphoglucomutase 1 and 2 (PGM1 and PGM2), Shikimic dehydrogenase (SKDH), 6-phosphoglucodehydrogenase (6-PGD), fluorescent esterase (FE) and phosphoglucose isomerase (PGI). PGM 1 and 2, 6-P and SKDH were resolved on buffer system 11 (Soltis et al, 1983), while FE and PGI were resolved on a Poulik buffer (Mitton et al, 1979). Recipes for the enzyme stains are found in Soltis et al (1983).

\section{Statistical analyses}

Several parameters commonly used to measure genetic diversity were calculated for each of the 10 sites. These were the proportion of polymorphic loci (P) among the six loci used, observed $\left(H_{\mathrm{o}}\right)$ and expected $\left(H_{\mathrm{e}}\right)$ heterozygosity and total number of alleles. $H_{\mathrm{e}}$ was calculated where $H_{\mathrm{e}}=1-\sum p_{i}^{2}$, where $p_{i}$ is the frequency of the $i$ th allele at that locus. To examine changes in genotypic diversity caused by clonal growth, we calculated the genotypic diversity statistic $D$ for each of our study plots (Ellstrand and Roose, 1987). Where $D=1-\sum\left\{\left(n_{i}\left(n_{i}-1\right)\right) /[N(N-1)]\right\}, \quad n_{i}$ is the number of

Table 1 Estimates of genetic diversity within each of the 10 study plots (the number of above-ground stems in each plot is shown in parentheses)

\begin{tabular}{lcccccc}
\hline Transect & Plot (N) & $\mathrm{A}_{e}$ & $\mathrm{H}_{o}$ & $\mathrm{H}_{e}$ & $\mathrm{~F}_{I S}$ & $\mathrm{D}$ \\
\hline 1 & CS (45) & 1.10 & 0.094 & 0.084 & -0.044 & 0.69 \\
1 & LE (48) & 1.22 & 0.158 & 0.160 & 0.124 & 0.92 \\
1 & MI (38) & 1.27 & 0.114 & 0.190 & 0.296 & 0.82 \\
1 & BS (47) & 1.26 & 0.194 & 0.196 & 0.002 & 0.90 \\
2 & CS (44) & 1.12 & 0.106 & 0.094 & -0.074 & 0.72 \\
2 & MI (44) & 1.12 & 0.102 & 0.097 & -0.020 & 0.60 \\
3 & CS (47) & 1.16 & 0.110 & 0.125 & $0.636^{*}$ & 0.73 \\
3 & LE (42) & 1.20 & 0.123 & 0.144 & 0.128 & 0.76 \\
3 & MI (48) & 1.10 & 0.069 & 0.080 & 0.075 & 0.60 \\
3 & BS (44) & 1.27 & 0.063 & 0.150 & $0.614^{*}$ & 0.76 \\
& & & & & & \\
Mean & (446 total) & 1.18 & 0.117 & 0.140 & 0.173 & 0.75 \\
& & & & & & \\
\end{tabular}

$A_{\mathrm{e}}$ : effective number of alleles; $H_{\mathrm{o}}$ : observed heterozygosity; $H_{\mathrm{e}}$ : expected heterozygosity; $F_{\text {IS: }}$ inbreeding coefficient; $D$ : multilocus diversity statistic. Mean values are calculated when all 446 individuals are pooled; ${ }^{*} P<0.05$. individuals of multilocus genotype $i$ and $N$ is the population size. The $D$ value ranges from 0 to 1 , where 0 reflects all individuals containing the same multilocus genotype, and 1 is where each individual has a unique multilocus genotype.

\section{Spatial dispersion of individuals}

As a result of the apparent change in the spatial distribution of individuals with age, we used a measure of spatial dispersion within each of the 10 plots. We employed a statistic $L(t)$, which is a modification of Ripley's $K(t)$, to test the spatial pattern of individuals, or stems, within a site relative to a random distribution at successively greater distance intervals (Ripley, 1977; Peterson and Squiers, 1995). The experimenter chooses the distance interval $(t)$ tested, and then spatial dispersion is tested for all increments of $t$ up to half the size of the plot. We calculated dispersion via $L(t)=t-[K(t) / \pi] 1 / 2$, and then plot $L(t)$ vs $t$ to examine the spatial dispersion of stems at all distance classes $t$; the parameter $L$ is favored over $K$ since the shape of $K$ with increasing $t$ is exponential, whereas $L$ fluctuates around zero for all $t$ when dispersion is random; $L(t)$ is negative when clumped and positive when even or hyperdispersed. We chose the increment of $t$ to be $0.5 \mathrm{~m}$; thus $L$ is calculated for $0.5 \mathrm{~m}$ and then at each successive $1 / 2 \mathrm{~m}$ interval until the largest distance interval, which is specified as $1 / 2$ the size of the smallest side of the plot. Each graph of $L(t)$ vs $t$ has a $95 \%$ confidence envelope, where the upper 95\% represents hyperdispersion and the lower $95 \%$ represents a clumped distribution, and $L(t)$ values between the upper and lower confidence intervals (CIs) correspond to random dispersion.

\section{Spatial genetic structure}

To examine the distribution of genotypes within each of the 10 plots, we estimated a coefficient of coancestry, $r_{i j}$. The parameter $r_{i j}$ measures the multilocus genetic correlation among pairs of individuals across a range of distance intervals (developed by Dr J Nason from Cockerham, 1969). For a given distance interval, all pairs of individuals that occur within it will be analyzed for coancestry. The $r_{i j}$ value for that distance interval is then presented as a mean value across all pairs analyzed. The coefficient of coancestry $r_{i j}$ is calculated as

$$
r_{i j}=\left\{\sum_{i j}\left[\left(p_{i}-p^{*}\right) /\left(p_{j}-p^{*}\right)\right] / k p^{*}\left(1-p^{*}\right)\right\}
$$

where $p^{*}$ is the frequency of allele $p$ in the population, $p_{i}$ and $p_{j}$ are the frequencies of allele $p$ in individuals $i$ and $j$, respectively, and $k$ is the number of pairs for which $r_{i j}$ is calculated. The six allozyme loci were used in conjunction with the two-dimensional map coordinates of each individual within a plot to generate $r_{i j}$ values for distances of 0.5 and up at a $0.5 \mathrm{~m}$ interval. The maximum distance interval depends upon the largest distance among any pair of individuals within a plot. A 95\% CI for $r_{i j}$ was generated by simulation through randomly assigning map positions to extant genotypes and then recalculating $r_{i j}$. This randomization procedure was repeated 19 times at each distance interval to generate 
Table 2 Estimates of allelic diversity and structure for each locus across all 10 plots

\begin{tabular}{lcccrc}
\hline Locus & $\mathrm{H}_{T}$ & $\mathrm{H}_{S}$ & $\mathrm{~F}_{S T}$ & \multicolumn{1}{c}{$\mathrm{F}_{I S}$} & \multicolumn{1}{c}{$\chi^{2}$} \\
\hline Pgm1 & 0.321 & 0.309 & 0.036 & 0.133 & $39.55(18)^{* * * *}$ \\
Pgm2 & 0.086 & 0.082 & 0.055 & 0.067 & $45.86(9)^{* * *}$ \\
SKDH & 0.071 & 0.066 & 0.075 & -0.049 & $62.91(9)^{* * * *}$ \\
6-Pgd & 0.101 & 0.098 & 0.029 & 0.009 & $24.09(9)^{* *}$ \\
FE & 0.224 & 0.215 & 0.038 & 0.317 & $26.31(9)^{* *}$ \\
PGI & 0.024 & 0.023 & 0.021 & 0.008 & $17.80(9)^{*}$ \\
Mean & 0.138 & 0.132 & 0.042 & 0.074 & \\
\hline
\end{tabular}

$H_{\mathrm{T}}$ and $H_{\mathrm{S}}$ are total and population level heterozygosities respectively. $F_{\mathrm{IS}}$ and $F_{\mathrm{ST}}$ are departures from Hardy-Weinberg equilibrium because of deviation within and among the 10 plots. $\chi^{2}$ tests for differences in allele frequency among the 10 sites. Mean values are averages among all loci. ${ }^{* * *} P<0.001,{ }^{* *} P<0.01,{ }^{*} P<0.05$.

a $95 \%$ confidence envelope around a mean of no spatial genetic structure. Only 19 simulations were performed because of limited access to computers where the analysis was run and because of our observation that when several simulations were repeated 99 times it made no difference in the outcome of the experiment.

\section{Results}

\section{Diversity}

No significant differences in genetic diversity were observed among the different aged sites or among the three transects (Table 1). We found significant differences $(P<0.05)$ in allele frequencies among the 10 sample sites at each locus (Table 2). However, the statistically significant differences in allele frequency among sites did not produce high $F_{\mathrm{ST}}$ values. Rather, $F_{\mathrm{ST}}$ values for all six loci were low, with a mean of 0.042 . Low $F_{\mathrm{ST}}$ values are consistent with the life history of the species, since outcrossing, wind-pollinated plants typically have low $F_{\text {ST }}$ values (Hamrick et al, 1993; Hamrick and Godt 1996). The significant differences in allele frequencies observed are at least partially explained by the high sensitivity with which significance is inferred when using large sample sizes. There was also no evidence for heterosis in these populations (Table 3). There was an increase in both observed and expected heterozygosity among the youngest (CS) and oldest (BS) sites (Table 3), but the increase was not monotonic. There was also an increase in the difference between observed and expected heterozygosity (Table 4 ) with age such that $F_{\text {IS }}$ was less in the CS (0.010) than in the BS sites (0.301). However, increases in both observed and expected heterozygosity with age were not significant (Table 3). Additionally, variance in allele frequency among sites was greater among individual sites (Table 2) than that observed among different age classes (Table 4). There was also no difference in the relative frequency of males and females along the chronosequence (Table 3).

\section{Spatial and clonal structure}

Along the chronosequence, we observed an increase in the grouping of individuals into multistemmed clusters. At the youngest sites on the island, no multistemmed
Table 3 Genetic diversity statistics for each age class pooled for all sites within that age class

\begin{tabular}{lcccccccc}
\hline Site & $\mathrm{N}$ & $\% \mathrm{P}$ & $\mathrm{AP}$ & $\mathrm{H}_{o}(\mathrm{SE})$ & $\mathrm{H}_{e}(\mathrm{SE})$ & $\mathrm{D}$ & $\mathrm{A}$ & $\mathrm{M} / \mathrm{F}$ \\
\hline $\mathrm{CS}$ & 135 & 100 & 2 & $0.104(0.026)$ & $0.103(0.043)$ & 0.73 & 12 & 0.98 \\
LE & 90 & 83.3 & 2 & $0.142(0.038)$ & $0.153(0.053)$ & 0.82 & 11 & 1.02 \\
MI & 130 & 100 & 2 & $0.093(0.026)$ & $0.119(0.043)$ & 0.70 & 12 & 0.92 \\
BS & 91 & 100 & 2 & $0.130(0.037)$ & $0.186(0.054)$ & 0.85 & 12 & 1.11 \\
Mean & 446 & 96.8 & 2 & $0.117(0.016)$ & $0.140(0.024)$ & 0.75 & 12 & 0.97
\end{tabular}

$N$ : number of individuals for each age class; $\% P$ : percent polymorphic loci; $H_{\mathrm{o}}$ : observed heterozygosity with standard errors in parentheses; $H_{\mathrm{e}}$ : expected heterozygosity with standard errors in parentheses; $D$ : index of multilocus genotypic diversity; $A$ : number of alleles present within a cohort. The relative number of males to females is presented as the quotient of the number of males divided by the number of females.

individuals were apparent, but in the oldest sections, most individuals were within multistemmed aggregates (Figure 2). We tested the significance of the observed change in spatial patterning along the chronosequence with Ripley's L. For all plots, the test statistic fell below the lower 95\% confidence bound (Figure 2), reflecting significant aggregation of stems. A random distribution was observed in only two sites (T1-MI and T3-LE), and only at a few of the intervals tested ( $t=5$ and 6 for T1-MI, and 7 and above for T3-LE). Thus, although there appears to be an increase in this spatial clustering with age, individuals at all age classes were significantly clumped.

The increase in multistemmed architecture along the chronosequence does not appear to be because of clonal growth. Few multistemmed clusters were composed of a single genotype. Clustering of unrelated individuals appears to be the consequence of a nonrandom distribution of individuals described above rather than of an increase in size and clonal spread individual genets. In the CS sites, individuals, particularly juveniles colonizing in 1997, were significantly clumped. Thus, the spatial aggregation observed in very early stages was maintained at all age classes and was independent of genotype. This lack of clonal structure is mirrored in the high $D$ value (Table 1 ). The $D$ statistic does not change consistently with age for any of the three transects (Table 1). Pooling similar aged sites also does not result in a consistent trend of increasing clonal structure (decreasing $D$ value) with age (Table 3 ). Values of $D$ are high given the level of allelic diversity observed, and suggest a general absence of clonal structure. Likewise, for all 10 plots the calculation of spatial genetic autocorrelation, $r_{i j}$, fell within the $95 \%$ confidence envelopes, indicating a lack of spatial genetic structure at all intervals tested (Figure 3). Estimates of $F_{\text {IS }}$ that may indicate clonal growth and reproduction varied among sites. The mean of $F_{\mathrm{IS}}$ for all sites is low (Table 1), suggesting no clonal structure, with two of the 10 sites (T3-CS and T3-BS) exhibiting significantly positive $F_{\text {IS }}$ values (Table 1). However, neither of these sites were observed to have a positive $r_{i j}$, nor did they have low $D$ values. 
a

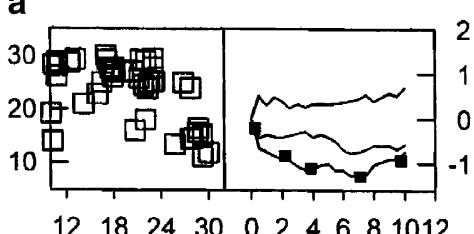

b

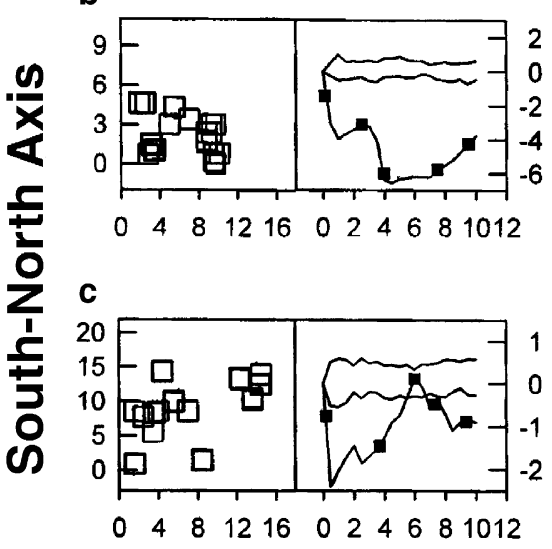

d

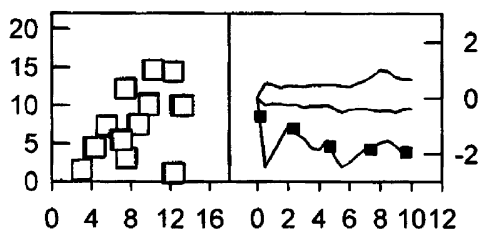

East-West Distance Interval g
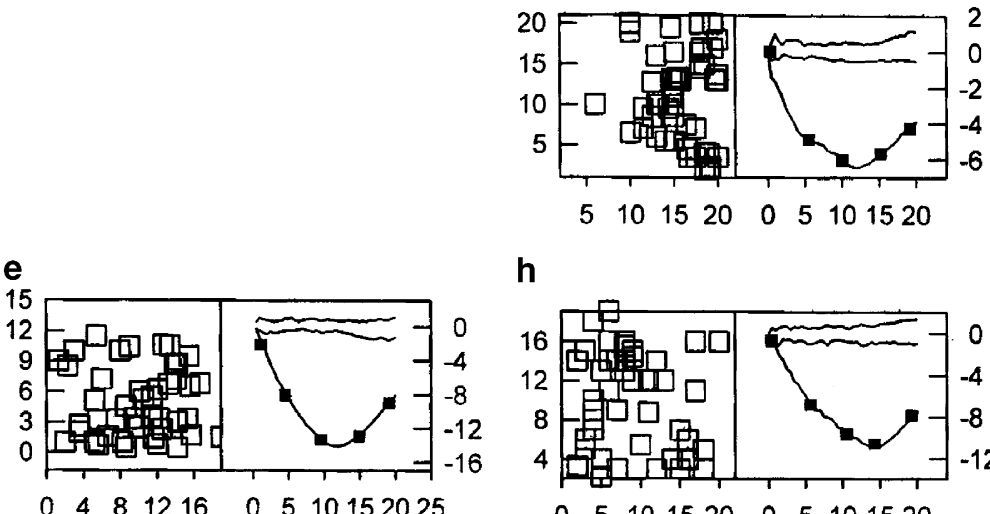

h

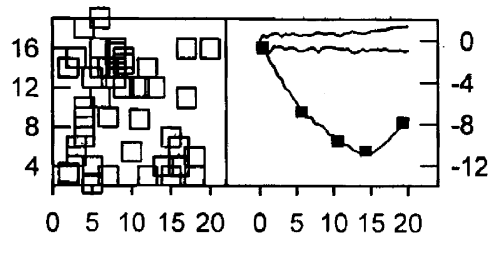

i

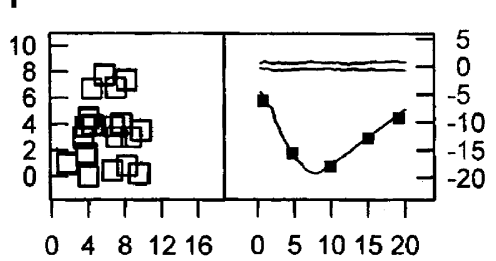

East-West Distance Interval

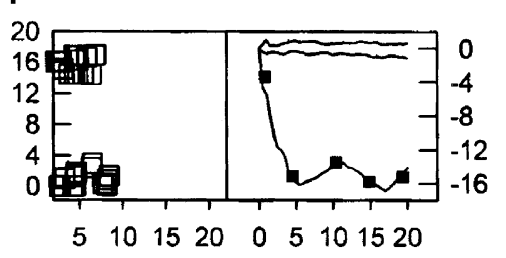

نُ

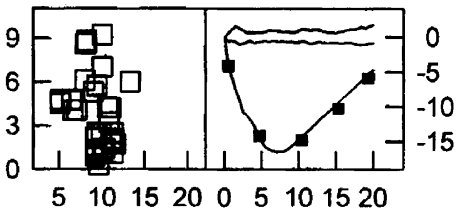

East-West Distance Interval

Figure 2 Scatter plots of all 10 study plots are shown with corresponding graphs of spatial structure, $L(t)$, of individuals within the plots. Graphs of spatial structure contain the test statistic, and a 95\% confidence envelope defining the upper and lower boundary of random dispersion. Values of $L(t)$ above the $95 \%$ CI are hyperdispersed, and those below are clumped. Plots are labeled by letter, with a-d representing the BS, MI, LE and CS plots of Transect 1. Likewise, (e) and (f) are MI and CE for transect 2, and g-j are BS, MI, LE and CS for transect 3 .

Table 4 Estimates for plots pooled within each age class

\begin{tabular}{lcccrc}
\hline Locus & $\mathrm{H}_{T}$ & $\mathrm{H}_{S}$ & $\mathrm{~F}_{S T}$ & $\mathrm{~F}_{I S}$ & $\chi^{2}$ \\
\hline Pgm1 & 0.321 & 0.319 & 0.005 & 0.163 & $8.3(6)$ \\
Pgm2 & 0.086 & 0.085 & 0.009 & 0.110 & $7.8(3)$ \\
SKDH & 0.071 & 0.070 & 0.014 & 0.015 & $12.1(3)^{*}$ \\
6-Pgd & 0.100 & 0.100 & 0.014 & 0.024 & $11.7(3)^{*}$ \\
FE & 0.233 & 0.217 & $0.030^{*}$ & 0.322 & $19.9(3)^{* *}$ \\
PGI & 0.024 & 0.024 & 0.006 & -0.018 & $4.5(3)$ \\
Mean & 0.138 & 0.136 & 0.010 & 0.103 & \\
\hline
\end{tabular}

$H_{\mathrm{T}}$ and $H_{\mathrm{S}}$ are total and population level heterozygosities, respectively. $F_{\mathrm{IS}}$ and $F_{\mathrm{ST}}$ are departures from Hardy-Weinberg equilibrium because of deviation within and among the 10 plots. $\chi^{2}$ tests for differences in allele frequency among the 10 sites. Mean values are averages among all loci. ${ }^{* *} P<0.01,{ }^{*} P<0.05$.

\section{Discussion}

Studies examining separate cohorts or age groups within populations for evidence of heterosis or increased genetic diversity offer mixed results. Some studies have found increased genetic diversity and heterozygosity, or de- creased genetic structure with increasing cohort age (Smyth and Hamrick, 1984; Giles and Goudet, 1997). Others have found little temporal differentiation among cohorts (Mahy et al, 1999; Schnabel and Hamrick, 1990; Linhart et al, 1981). In this study, we have only weak evidence for increased diversity and decreased genetic structure with increasing cohort age. There was a slight but nonsignificant increase in most genetic diversity parameters with age (Table 3), which was mirrored by low, but significant, $F_{\mathrm{ST}}$ values among the four age classes (Table 4). Nor is their compelling evidence for heterosis in this population. In fact, we observed a decrease in observed heterozygosity relative to expected heterozygosity with increasing population age (Table 3). If this difference was significant, it would suggest increased inbreeding or increased spatial genetic structure in the older age classes. However, we did not observe a significant increase in clonal structure as measured by the multilocus genotypic index, $D$. Although we do not see a decrease in $D$ with age, and hence the suggestion of little clonal structure, we did see an increase in the number of multistemmed clusters composed of a single genotype. The observed increase in $F$ may actually be a result in part of increased clonal 


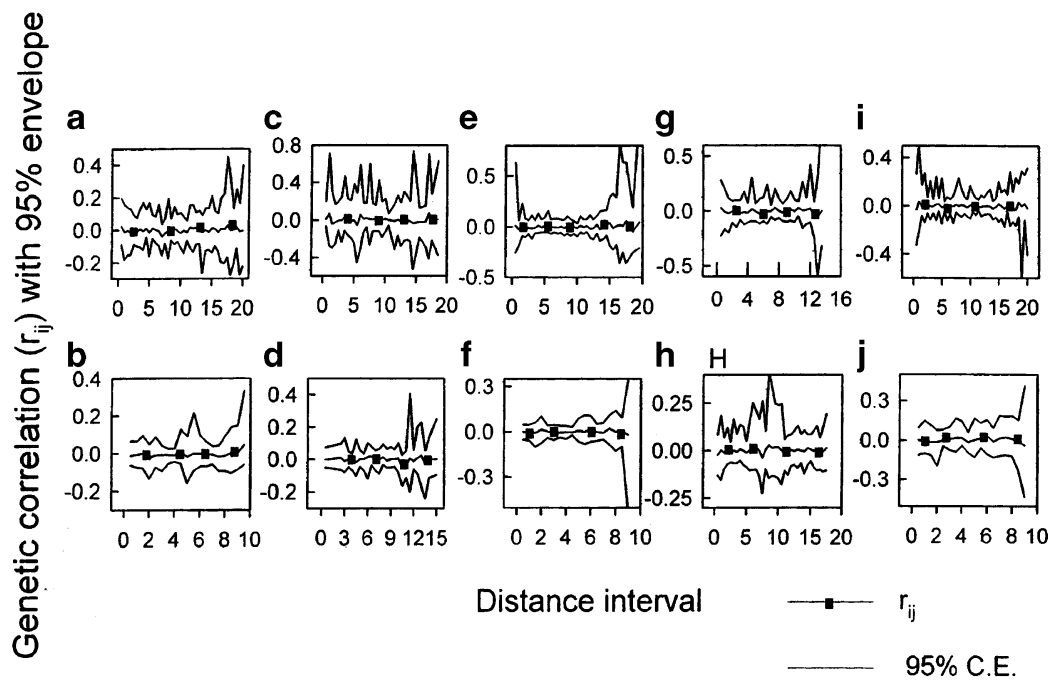

Figure 3 Plots of $r_{i j}$, which measures spatial genetic autocorrelation, are shown for all 10 study plots. Each panel shows the test statistic and a 95\% confidence envelope. The $r_{i j}$ statistic is plotted over a series of distance intervals as described in the text. Values of $r_{i j}$ that lie above the 95\% CI imply increased relatedness among pairs of individuals at that distance class, while values below the $95 \%$ CI imply decreased relatedness relative to random. Values of $r_{i j}$ that fall within the $95 \%$ CI suggest that individuals are no more or less related than expected at random.

structure. The observation of a slight, though nonsignificant, increase in genetic diversity along the chronosequence is difficult to explain since the lack of recruitment in older cohorts precludes the addition of genetic diversity because of gene flow. Levels of genetic diversity in the younger sites were relatively high, indicating that there is little evidence for a founder effect in these newly colonized sites.

Analysis of the spatial structuring of individuals along the chronosequence with Ripley's $L$ demonstrated a nonrandom spatial distribution for all age classes (Figure 2 ). This was not surprising since differences in microelevation regulate the distribution of newly established plants. The spatial patterning of $M$. cerifera on Hog Island suggests that clonal growth may increase with age. In contrast, the two measures used to infer clonal structure suggested that little clonal growth occurs in these populations of $M$. cerifera. The multilocus genotypic diversity statistic $D$ did not decrease with age (Table 3 ), and genetic analyses of the multistemmed clusters showed that relatively few are composed of a single genotype. Rather, multistemmed clusters are typically composed of two or more genetically distinct individuals growing adjacent to one another. Although most clusters of stems are composed of genetically distinct individuals, there is an increase in the number of multistemmed clones relative to the CS sites. Therefore, the initial effects of seed dispersal and patchy establishment on the spatial distribution of individuals are maintained in the older aged sites. The limited clonal reproduction observed enhanced the initial spatial clustering observed in the colonizing sites, yet without significantly increasing spatial genetic structure.

Furnier et al (1987) investigated the clonal structure of whitebark pine, Pinus albicaulis, which exhibits a similar multistemmed architecture. They found that clusters of individuals were composed of genetically distinct individuals, but that individuals within a given cluster are more closely related to one another than they are to individuals in separate clusters. The behavior of Clark's nutcracker, Nucifraga columbiana, likely generates this family structure through the caching of seeds from a single maternal plant, or kin-structured dispersal. This pattern of family structure results in a nonrandom distribution of individuals and alleles in space and hence some positive spatial genetic autocorrelation. Likewise, Hamrick et al (1993) found significant spatial genetic heterogeneity in a small tropical tree Swartzia simplex var. ochnaceae, which is also bird dispersed. They observed that $S$. simplex had the finest scale of genetic structure of the three species studied, and little decrease in genetic structure with age occurred, unlike the other, larger, tree species examined.

We found no evidence for the structuring of multilocus genotypes in space at any distance interval (Figure 3). Smouse and Peakall (1999) suggest that studies that fail to find spatial genetic structure may be flawed because of the limited resolution of methods such as Moran's I, which are based upon the spatial distribution of individual alleles. However, the measure $r_{i j}$ is a true multilocus estimate of genetic correlation among spatially distributed genotypes (after Cockerham, 1969; see also Heywood, 1991 and Loiselle et al, 1995); yet we nonetheless failed to detect any spatial genetic structure. Our results suggest that individuals within a cluster are no more closely related to one another than to individuals in other clusters. The nonrandom spatial distribution of individuals contrasts with the random spatial distribution of alleles and suggests a complete absence of family-structured dispersal. The nonrandom aggregation of individuals into multistemmed clusters is similar for $M$. cerifera and $P$. albicaulis, but is likely because of different mechanisms, seed caching on the one hand and a pattern of patchy recruitment and establishment on the other. Kalisz et al (2001) used a similar multilocus estimator of spatial genetic structure in Trillium grandi- 
florum and observed differences in spatial genetic structure among different aged cohorts. They attributed the nonrandom distribution at later aged stages to the limited seed dispersal, but the lack of spatial genetic structure at younger aged cohorts was attributable to random pollen dispersal among individuals within the population. With $M$. cerifera, there does not appear to be limited seed dispersal, such that the nonrandom spatial distribution of individuals is uncoupled from the random distribution of genotypes and alleles. This is likely attributable to long-range seed dispersal by $D$. coronata, without associated kin-structured dispersal, as well as a random pollen gene pool.

The random spatial distribution of alleles and genotypes on Hog Island, in conjunction with the absence of pronounced genetic structure at any spatial scale as inferred through spatial genetic autocorrelation and $F_{\mathrm{ST}}$, suggests that the entire island is a single large and nearly panmictic unit. The nonrandom spatial distribution of individuals appears to have no effect upon genetic diversity or structure in this population, and while the moderate increase in clonal structure may affect genotype frequencies, it has no overall effect upon levels of genetic diversity. The genetic structure of the population appears to be determined by a combination of gene flow and environmental disturbance, rather than by genetic drift or natural selection. The absence of significant spatial genetic structure at any scale suggests a primary role of gene flow in determining the genetic structure of population. The absence of heterosis with age may be attributed to the stochastic growing environment, where environmental disturbance rather than selection determines survival.

\section{References}

Bush RM, Smouse PE (1992). Evidence for the adaptive significance of allozymes in forest trees. New Forests 6: 179196.

Cockerham CC (1969). Variance of gene frequencies. Evolution 23: 72-78.

Crawford ER, Young DR (1998). Comparison of gaps and intact shrub thickets on an Atlantic coast barrier island. Am Mid Nat 140: 68-77.

Dudash MR, Carr DE (1998). Genetics underlying inbreeding depression in Mimulus with contrasting mating systems. Nature 393: 682-684.

Dumolin-Lapegue D, Demesure B, Fineschi S, Le Corre V, Petit RJ (1997). Phylogeographic structure of White Oaks throughout the European continent. Genetics 146: 1475-1487.

Ellstrand NC, Roose ML (1987). Patterns of genotypic diversity in clonal plant species. Am J Bot 74: 123-131.

Fore SA, Hickey RJ, Guttman SI, Vankat JL (1992). Temporal differences in genetic diversity and structure of sugar maple in an old-growth forest. Can J For Res 22: 1504-1509.

Furnier GR, Knowles P, Clyde MA, Danick BP (1987). Effects of avian seed dispersal on the genetic structure of whitebark pine populations. Evolution 41: 607-612.

Giles BE, Goudet J (1997). Genetic differentiation in Silene dioica metapopulations: estimation of spatiotemporal effects in a successional plant species. Am Nat 149: 507-526.

Hamrick JL, Godt MJW (1996). Effects of life history traits on genetic diversity in plant species. Phil. Trans. Roy. Soc. London Biol. Sci. 351: 1291-1298.
Hamrick JL, Murawski DA, Nason JD (1993). The influence of seed dispersal mechanisms on the genetic structure of tropical tree populations. Vegetatio 108: 281-297.

Hayden BP, Dueser RD, Callahan JT, Shugart HH (1991). Longterm Research at the Virginia Coast Reserve: Modeling a Highly Dynamic Environment. Bioscience 41: 310-318.

Hayden BP, Santos MCFV, Shao G, Kochel RC (1995). Geomorphologic controls on coastal vegetation at the Virginia Coast reserve. Geomorphology 13: 283-300.

Heywood JS (1991). Spatial analysis of genetic variation in plant populations. Ann Rev Eco Syst 22: 335-355.

Ingvarsson PK (1998). Kin-structured colonization in Phalacrus substriatus. Heredity 80: 456-463.

Kalisz S, Nason JD, Hanzawa FM, Tonsor SJ (2001). Spatial population genetic structure in Trillium grandiflorum: the roles of dispersal, mating, history and selection. Evolution 55: 1560-1568.

Linhart YB, Mitton JB, Sturgeon KB, Davis ML (1981). Genetic variation in space and time in a population of Ponderosa pine. Heredity 46: 407-426.

Loiselle BA, Sork VL, Nason JD, Graham C (1995). Spatial genetic structure of a tropical understory shrub, Psychotria officinalis (Rubiaceae). Am J Bot 82: 1420-1425.

Mahy G, Vekemans X, Jacquemart A-L (1999). Patterns of allozymic variation within Calluna vulgaris populations at seed bank and adult stages. Heredity 82: 432-440.

Mitton JB, Grant MC (1984). Associations among protein heterozygosity, growth rate, and developmental homeostasis. Ann Rev Eco Syst 15: 479-499.

Mitton JB, Linhart YB, Sturgeon KB, Hamrick JL (1979). Allozyme polymorphisms detected in mature needle tissue of Ponderosa pine. J Hered 70: 86-89.

Parker KC, Hamrick JL (1992). Genetic diversity and clonal structure in a columnar cactus, Lophocereus schottii. Am J Bot 79: 86-96.

Peterson CJ, Squiers ER (1995). An unexpected change in spatial pattern across 10 years in an aspen white-pine forest. J Ecol 83: 847-855.

Radford AE, Ahles HE, Bell CR (1968). Manual of the Vascular Flora of the Carolinas. Chapel Hill, University of North Carolina Press.

Ripley BD (1977). Modeling spatial patterns. J Royal Stat Soc 39: 172-212.

Savolainen O, Hedrick P (1995). Heterozygosity and fitness: no association in Scots pine. Genetics 140: 755-766.

Schierup MH (1998). The effect of enzyme heterozygosity on growth in a strictly outcrossing species, the self-incompatible Arabis petraea (Brassicaceae). Hereditas 128: 21-31.

Schnabel A, Hamrick JL (1990). Organization of genetic diversity within and among populations of Gleditsia triacanthos (Leguminosae). Am J Bot 77: 1060-1069.

Shao G, Young DR, Porter JH, Hayden BP (1998). An integration of remote sensing and GIS to examine the responses of shrub thicket distributions to shoreline changes on Virginia barrier islands. I Coastal Res 14: 299-307.

Smouse PE, Peakall R (1999). Spatial autocorrelation analysis of individual multiallele and multilocus genetic structure. Heredity 82: 561-573.

Smyth CA, Hamrick JL (1984). Variation in estimates of outcrossing in musk thistle populations. J Hered 75 : 303-307.

Soltis DE, Haufler CH, Darrow DC, Gastony GJ (1983). Starchgel electrophoresis of ferns - a compilation of grinding buffers, gel and electrode buffers, and staining schedules. Am Fern J 73: 9-27.

Widen B, Cronberg N, Widen M (1994). Genotypic diversity, molecular markers and spatial distribution of genets in clonal plants. In: Soukupova L, Marshall C, Hara T, Herben T (eds) Plant Clonality; Biology and Diversity, Opulus Press: Uppsala, Sweden. pp 139-157. 
Young DR, Erickson DL, Semones SW (1994). Salinity and the small-scale distribution of 3 barrier island shrubs. Can J Bot 72: 1365-1372.

Young DR, Sande E, Peters GA (1992). Spatial relationships of Frankia and Myrica cerifera on a Virginia, USA barrier island. Symbiosis 12: 209-220.
Young DR, Shao G, Brinson MM (1995a). The impact of the October 1991 northeastern storm on barrier-island shrub thickets (Myrica cerifera). J Costal Res 11: 1322-1328.

Young DR, Shao G, Porter JH (1995b). Temporal and spatial growth dynamics of barrier island shrub thickets. Am J Bot 82: 638-645. 